\title{
Ventana al mundo de la ciencia
}

"Lo único que importa es el esfuerzo"

Antoine de Saint-Exupery

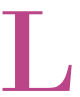

a revista ESTOA es la ventana de nuestra institución al mundo de la ciencia, y es sobre todo el resultado del esfuerzo sostenido por un equipo de profesionales universitarios preocupados por la calidad de la investigación en materia de arquitectura y urbanismo. Nuestro reto es ofrecer a un público lego o experimentado una ventana al mundo de la ciencia que, en el ámbito iberoamericano, se hace en estas disciplinas.

Y este desafío se afronta desde el altruismo, pues como no podría ser de otro modo, surge del simple amor a la investigación de calidad. Es por ello que procuramos en todos los pasos del proceso editorial de ESTOA resguardar la ética y las buenas prácticas, tan susceptibles hoy de ser corrompidas por intereses espurios.

El acceso abierto (AA) a la información es, por otra parte, un asunto en el que nos interesamos sobremanera en el Centro de Investigación (CINA) de la Facultad de Arquitectura y Urbanismo de la Universidad de Cuenca. Somos totalmente conscientes de que los aportes necesitan ser difundidos con la mayor amplitud, y que hacer visibles los artículos de ESTOA sin restricciones sólo puede ayudar al desarrollo de la investigación de nuestra región, América Latina. Es por ello que tratamos de difundir todos los documentos editados por la Facultad en AA. La revista ESTOA se publica en abierto "vía diamante"1, y se propaga con ayuda de las múltiples bases de datos en que está indexada como fuente académica de referencia. Por otro lado, los libros, catálogos y documentos docentes son enviados por los miembros del CINA al repositorio de la Fundación Dialnet, que además de crear para ellos referencias informativas que faciliten al amplio número de usuarios de esta base de datos -la más visitada en el ámbito hispanohablante- su localización, los hace disponibles a texto completo para su descarga.
Nos hemos planteado desafíos singulares y estamos acometiéndolos desde diversos frentes. Si por un lado nos importa estar presentes en bases de datos internacionales que nos den difusión y un espaldarazo de credibilidad, por otra parte, nuestra primera ambición es asegurar que los contenidos que ofrece ESTOA sean de gran calidad. Lograrlo tan sólo puede ser posible estableciendo filtros de calidad exigentes, y en esta dinámica la revista se ha convertido en un artefacto para la mejora y optimización de los trabajos que nos han sido presentados, al punto que recibimos a menudo el agradecimiento de académicos que valoran sobremanera las críticas que se les han hecho, llegando incluso a darse este caso con autores de artículos que no han sido finalmente aceptados.

Nosotros no somos jueces ni nos erigimos como tales. La comunidad académica que respalda a la revista y la apoya en sus procesos de revisión son los que dirimen la pertinencia o no de un documento. Nuestra labor es solamente crear el engranaje adecuado para el examen y velar por que el producto destilado final sea de excelencia.

Por consiguiente, la inversión que la Facultad de Arquitectura y Urbanismo de la Universidad de Cuenca hace por elaborar un producto de calidad como es la revista ESTOA, en realidad es un obsequio que se hace al universo de la investigación en favor la de difusión libre y sin fronteras de la ciencia, concordando totalmente con la premisa de que el conocimiento debe ser compartido. El saber es un bien que crece cuanto más se comparte.

Ing. Fabián Cazar Almache fabian.cazar@ucuenca.edu.ec Ph.D. José Luis Crespo Fajardo luis.crespo@ucuenca.edu.ec

Comité Editorial de ESTOA

Cuenca, diciembre de 2017
${ }^{1}$ La vía diamante -ocasionalmente denominada vía platino- define a las revistas que ponen sus artículos en abierto sin solicitar el pago de APCs (Article Processing Charges). En su lugar, el equipo editorial de la revista trabaja sin intereses remuneratorios, generalmente bajo el auspicio de una institución académica. 